\title{
PURIFICAÇÃO E CARACTERIZAÇÃO DE $\alpha$-GALACTOSIDASES DE SEMENTES DE Platymiscium pubescens Micheli ${ }^{1}$
}

Giordani de Oliveira², Valéria Monteze Guimarães², Eduardo Euclydes de Lima e Borges ${ }^{3}$, Lilian da Silva Fialho $^{2}$, Maria Goreti de Almeida e Oliveira² e Sebastião Tavares de Rezende ${ }^{2}$

\begin{abstract}
RESUMO - Este trabalho objetivou foi determinar a composição bioquímica de sementes de espécies florestais e caracterizar a enzima $\alpha$-galactosidase de sementes germinadas de Platymiscium pubescens. Os maiores teores de lipídios foram determinados em sementes de Chorisia speciosa, Caesalpinia peltophoroides, Tabebuia serratifolia e Tabebuia velanedae, enquanto sementes de Enterolobium contortisiliquum, Schizolobium parahyba e Cassia grandis apresentaram os maiores teores protéicos. A $\alpha$-galactosidase catalisa a hidrólise dos oligossacarídeos de rafinose, em sementes de leguminosas, durante a germinação. A maior atividade da $\alpha$-galactosidase foi detectada em sementes de Platymiscium pubescens após 72 h de embebição. Duas formas de $\alpha$-galactosidases, C1 e C2, foram purificadas de sementes germinadas de P. pubescens, usando-se fracionamento com sulfato de amônio e cromatografias de filtração em gel e de afinidade. Essas enzimas apresentaram atividade máxima em $\mathrm{pH}$ 5,5 e a $50-55^{\circ} \mathrm{C}$. Os valores de $\mathrm{K}_{\mathrm{m} \text { ap }}$ das formas $\mathrm{C} 1$ e $\mathrm{C} 2$, para o substrato $\rho$-nitrofenil- $\alpha$-D-galactopiranosídeo, foram de 0,54 $\mathrm{mM}$ e 0,78 $\mathrm{mM}$, e para a rafinose, de 4,64 $\mathrm{mM}$ e 5,09 $\mathrm{mM}$, respectivamente. Essas enzimas exibiram estabilidade térmica moderada, mantendo $70 \%$ da atividade original após $3 \mathrm{~h}$ de incubação a $45^{\circ} \mathrm{C}$. A atividade enzimática da $\mathrm{C} 1$ e $\mathrm{C} 2$ foi totalmente perdida na presença de $\mathrm{CuSO}_{4}$ e dodecil sulfato de sódio (SDS). Tais enzimas também hidrolisaram melibiose, rafinose e estaquiose, indicando potencial para aplicações biotecnológicas.
\end{abstract}

Palavras-chave: Platymiscium pubescens, $\alpha$-galactosidase, sementes, germinação e purificação.

\section{PURIFICATION AND CHARACTERIZATION OF $\alpha$-GALACTOSIDASES FROM Platymiscium pubescens Micheli SEEDS}

\begin{abstract}
The objective of this work was to determine seed biochemical composition of forest species and to characterize $\alpha$-galactosidase enzyme of germinated seeds of Platymiscium pubescens. The highest lipid levels were found in seeds of Chorisia speciosa, Caesalpinia peltophoroides, Tabebuia serratifolia and Tabebuia velanedae, whereas seeds of Enterolobium contortisiliquum, Schizolobium parahyba and Cassia grandis showed the highest protein levels. $\alpha$-galactosidase catalyzes the hydrolyzis of raffinose oligossacarides in legume seeds during germination. The highest activity of $\alpha$-galactosidase was found in seeds of Platymiscium pubescens after $72 \mathrm{~h}$ of soaking in the water. Two forms of $\alpha$-galactosidases, C1 and C2, were purified from germinated seeds of $\boldsymbol{P}$. pubescens, using partition with ammonium sulfate, and gel filtration and affinity chromatographies. These enzymes presented maximum activity at $\mathrm{pH} 5.5,50-55^{\circ} \mathrm{C} . \mathrm{K}_{\text {map }}$ values in the $\mathrm{Cl}$ and $C 2$ forms for $\rho$-nitrophenyl- $\alpha$-D-galactopyranoside substrate were $0.54 \mathrm{mM}$ and $0.78 \mathrm{mM}$, and 4.64
\end{abstract}

\footnotetext{
${ }^{1}$ Recebido em 13.02.2004 e aceito para publicação em 20.04.2005.

${ }^{2}$ BIOAGRO/DBB da Universidade Federal de Viçosa, 36570-000, Viçosa-MG, Brasil.

${ }^{3}$ Departamento Engenharia Florestal da Universidade Federal de Viçosa.
} 
$\mathrm{mM}$ and $5.09 \mathrm{mM}$ for raffinose, respectively. These enzymes showed moderate thermal stability, maintaining $70 \%$ of the original activity after $3 \mathrm{~h}$ incubation at $45^{\circ} \mathrm{C}$. The C1 and C2 enzymatic activity was totally lost in the presence of $\mathrm{CuSO}_{4}$ and sodium dodecyl sulfate (SDS). These enzymes also hydrolyzed melibiose, raffinose and stachyose, indicating a potential for biotechnological applications.

Keywords: Platymiscium pubescens, $\alpha$-galactosidase, seeds, germination, purification.

\section{INTRODUÇÃO}

Além da importância das espécies florestais para o reflorestamento de áreas degradadas e conservação da biodiversidade (CARNEIRO et al., 1998), o estudo das suas sementes tem merecido destaque em razão das reservas de nutrientes e das enzimas hidrolíticas ativas durante a germinação.

As espécies florestais Cassia grandis, Schizolobium parahyba, Tachigali multijuga, Tabebuia serratifolia, Tabebuia velanedae, Enterolobium contortisiliquum, Platymiscium pubescens, Chorisia speciosa, Caesalpinia peltophoroides, Senna macranthera e Cedrela fissil apresentam diversas aplicações. Em razão das características de cada espécie, elas são mais apropriadamente indicadas para a produção de madeira usada na construção civil e na geração de energia, indústria de papel e celulose, extração de componentes químicos, alimentação animal e humana, apicultura, medicina, paisagismo e reflorestamento (CARVALHO, 1994). Platymiscium pubescens var. pubescens é uma espécie arbórea identificada pelos nomes de tamborilda-mata, timburi, timburil ou jacarandá-branco. De acordo com Klitgaard (1995), o “habitat” da espécie é o Cerrado, embora Marangon (1999) a identifique como de Floresta Estacional Semidecidual, ocorrendo em altitudes de 300 a 750 m. Predomina na Bahia, Espírito Santo, Distrito Federal e Minas Gerais. A espécie é de vegetação secundária, sendo a sua madeira usada para construção de moirão de cerca, além de ser utilizada como planta ornamental e de reflorestamento (KLITGAARD, 1995).

A enzima $\alpha$-galactosidase (E.C.3.2.1.22, $\alpha$-Dgalactosídeo galacto-hidrolase) é uma exoglicosidase que hidrolisa ligações $\alpha-1,6$ de resíduos de galactosil em galacto-oligossacarídeos e galactomananas (FUJIMOTO et al., 2003). Em plantas, essa enzima vem sendo especialmente investigada em sementes durante a germinação(CORCHETEe GUERRA, 1987; BHASKAR et al., 1990; GUIMARÃES et al., 2001), mas também está presente em folhas (SMART e PHARR, 1980), raiz (BOM et al., 1988) e frutos (GAO e SCHAFFER, 1999).
Múltiplas formas de $\alpha$-galactosidases ocorrem em plantas, apresentando diferenças em suas propriedades bioquímicas e cinéticas e em suas massas moleculares e exibindo especificidades diferentes por substratos naturais e sintéticos (DEY e PRIDHAM, 1972; KIM et al., 2002).

Dois tipos de carboidratos são armazenados no endosperma de leguminosas: oligossacarídeos de rafinose (RO) nos vacúolos e galactomananas nas células de parede (DEY, 1980). Os RO são formados de uma molécula de sacarose cujo resíduo glicosil está ligado com um a nove resíduos de galactose por ligação $\alpha-(1,6)$. Galactomananas são polissacarídeos compostos de uma cadeia principal formada de resíduos de D-manose unidos por ligação $\beta$-1,4 e ramificada em variadas extensões com unidades de D-galactose em ligações $\alpha-1,6$ (REID, 1985).

Durante a germinação e crescimento da plântula, reservas do cotilédone são degradadas e seus produtos, translocados para os pontos de crescimento do embrião e da plântula em desenvolvimento, em que são usados como fonte de carbono e energia para vários processos metabólicos (KANDLER e HOPF, 1980). A maioria das atividades enzimáticas, especialmente a da $\alpha$ galactosidase, aumenta com a embebição e germinação das sementes (CORCHETE e GUERRA, 1987; KONTOS e SPYROPOULOS, 1996; GUIMARÃES et al., 2001). Além do envolvimento fisiológico na germinação de sementes, as $\alpha$-galactosidases apresentam potencial para diversas aplicações biotecnológicas, como no branqueamento da polpa na indústria de papel, na mudança de propriedades gélicas de galactomananas (BULPIN et al., 1990) e na hidrólise de oligossacarídeos não-digeríveis presentes em produtos de soja (GUIMARÃES et al., 2001).

Diversas $\alpha$-galactosidases já foram purificadas e caracterizadas a partir de sementes, durante a germinação, como em Cassia sericea (BHASKAR et al., 1990) e Sesbania marginata (FALCO et al., 2000), mas a maioria dos estudos de atividade enzimática e da composição 
bioquímica das sementes se refere a espécies já utilizadas na alimentação, como soja (GUIMARÃES et al., 2001), lentilha (CORCHETE e GUERRA, 1987), ervilha (DEY e PRIDHAM, 1972) e feijões (DHAR et al., 1994). De acordo com Borges et al. (2002), há uma grande carência de informações fisiológicas e bioquímicas concernentes à composição e germinação das sementes de espécies florestais arbóreas nativas.

O objetivo do presente trabalho foi ampliar o conhecimento sobre a composição bioquímica de algumas sementes de espécies florestais, bem como identificar, entre as estudadas, uma espécie florestal que apresentasse a enzima $\alpha$-galactosidase com potencial para aplicação biotecnológica.

\section{MATERIAL E MÉTODOS}

Sementes das espécies florestais Cassia grandis, Schizolobium parahyba,, Tachigali multijuga, Tabebuia serratifolia, Tabebuia velanedae, Enterolobium contortisiliquum, Platymiscium pubescens, Chorisia speciosa, Caesalpinia peltophoroides, Cedrela fissilis e Senna macranthera foram fornecidas pelo Laboratório de Silvicultura do Departamento de Engenharia Florestal da UFV, enquanto as sementes das espécies Vigna umbellata, Pisum sativum e Glycine max, pela EPAMIG/ Viçosa.

Para avaliar a atividade de $\alpha$-galactosidase durante a germinação, amostras contendo 20 sementes foram colocadas em papel Germitest umedecido e incubadas por $24,48,72$ e $96 \mathrm{~h}$, a $27^{\circ} \mathrm{C}$. As sementes germinadas foram trituradas em tampão acetato de sódio a $100 \mathrm{mM}$ e pH 5,0 (uma semente para cada $1 \mathrm{~mL}$ de tampão). $\mathrm{O}$ extrato foi centrifugado a $17.200 \mathrm{x} \mathrm{g}$, por $30 \mathrm{~min}$, a $4{ }^{\circ} \mathrm{C}$, e o sobrenadante, utilizado para a determinação da atividade enzimática e da concentração de proteínas solúveis.

O ensaio-padrão da atividade de $\alpha$-galactosidase foi realizado usando-se uma mistura de reação contendo 650-750 $\mu \mathrm{L}$ de tampão acetato de sódio $100 \mathrm{mM}, \mathrm{pH}$ 5,0 , adicionando de 0 a $100 \mu \mathrm{L}$ da preparação enzimática e $250 \mu \mathrm{L}$ de $\rho$-nitrofenil- $\alpha$-D-galactopiranosídeo ( $\rho$ NP $\alpha \mathrm{Gal})$, ou outros substratos sintéticos. A reação foi incubada por 15 a $30 \mathrm{~min}$, a $37^{\circ} \mathrm{C}$, e paralisada pela adição de $1 \mathrm{~mL}$ de carbonato de sódio a 0,5 M. Uma unidade (U) de enzima foi definida como a quantidade de proteína necessária para produzir $1 \mu \mathrm{mol}$ de $\rho$-nitrofenol por minuto. Os efeitos do $\mathrm{pH}$ e da temperatura na atividade das frações enzimáticas foram determinados em $\mathrm{pH}$ de 3,0 a 7,5 e em temperaturas variando de 20 a $70^{\circ} \mathrm{C}$. Para a determinação da estabilidade térmica, as frações enzimáticas foram pré-incubadas por vários períodos de tempo, a 45 e $50^{\circ} \mathrm{C}$, e a atividade residual foi determinada pelo ensaio-padrão. Para a determinação das atividades com os substratos rafinose, estaquiose e sacarose, usou-se uma mistura de reação contendo $650 \mu \mathrm{L}$ de tampão acetato de sódio a 100 mM, pH 5,0, adicionando $100 \mu \mathrm{L}$ de extrato enzimático e $250 \mu \mathrm{L}$ de solução de substrato a $20 \mathrm{mM}$. O açúcar redutor produzido foi quantificado pela reação com $1 \mathrm{~mL}$ de 3,5 dinitrossalicilato (MILLER, 1956). Os ensaios com os substratos melibiose, lactose e maltose foram feitos usando-se as mesmas condições de reação anteriormente descritas, e a quantidade de glicose formada foi determinada pelo método da glicose-oxidase (BERGMEYER e BERNT, 1974). As determinações da atividade de $\alpha$-galactosidase são os valores médios de ensaios em triplicata, nos quais os desvios-padrão foram menores que $10 \%$.

As $\alpha$-galactosidases de tamboril-da-mata foram purificadas por fracionamento com sulfato de amônio (30-50\%), e o precipitado obtido foi ressuspendido e submetido à filtração em gel, em coluna Sephacryl S-200 (80 x $3 \mathrm{~cm})$, equilibrada com tampão acetato de sódio a $25 \mathrm{mM}$, pH 5,0. As proteínas foram eluídas com o mesmo tampão, com fluxo de $24 \mathrm{~mL} \cdot \mathrm{h}^{-1}$. A fração enzimática proveniente da coluna Sephacryl S-200 foi submetida à cromatografia de afinidade em coluna $(17 \mathrm{x} 1 \mathrm{~cm}) \mathrm{de}$ Concanavalina A Sepharose 4B, equilibrada com tampão acetato de sódio a $100 \mathrm{mM} \mathrm{e} \mathrm{pH} \mathrm{5,0,} \mathrm{contendo} \mathrm{MnCl}_{2}$, $\mathrm{MgCl}_{2} \mathrm{e} \mathrm{CaCl}_{2}$ a $1,0 \mathrm{mMe} 0,9 \% \mathrm{de} \mathrm{NaCl}$. As proteínas foram eluídas com o mesmo tampão, acrescido de 0,1 M de metil$\alpha$-D-manosídeo, com fluxo de $24 \mathrm{~mL} \cdot \mathrm{h}^{-1}$.

Experimentos cinéticos foram feitos a $37^{\circ} \mathrm{C} \mathrm{e} \mathrm{pH}$ 5,0. Para a determinação dos valores de $\mathrm{K}_{\mathrm{M} \text { ap }}$ e $\mathrm{V}_{\text {max ap }}$ das $\alpha$-galactosidases, as concentrações finais de $\rho \mathrm{NP} \alpha \mathrm{Gal}$ foram de 0,$1 ; 0,2 ; 0,4 ; 0,75 ; 1,0 ; 1,5 ; \mathrm{e} 2,0 \mathrm{mM}$ e as concentrações finais de melibiose e rafinose, de 5, 10 , 20, 30 e $40 \mathrm{mM}$. Os valores de $\mathrm{K}_{\mathrm{M} \text { ap }} \mathrm{e}_{\text {max ap }}$ foram determinados pela curva de Michaelis-Menten, utilizando-se o programa Curve Expert, versão 1.3, para Windows (HYAMS, 1997). Os efeitos de íons, agentes redutores e açúcares na atividade enzimática, foram testados utilizando-se ensaios-padrão, cujas amostras das enzimas foram pré-incubadas com cada um dos compostos testados por $15 \mathrm{~min}$ a $40{ }^{\circ} \mathrm{C}$.

R. Árvore, Viçosa-MG, v.29, n.4, p.535-543, 2005 
A concentração de proteínas foi determinada pelo método de Bradford (1976), utilizando-se curva-padrão construída com albumina sérica bovina (BSA). No processo de purificação das $\alpha$-galactosidases, a concentração de proteínas foi determinada pelo método de Lowry, como o descrito em Petterson (1979). O teor protéico nas sementes foi determinado pelo método de Kjeldahl, empregando-se o fator 6,25 para a conversão de nitrogênio em proteína (AOAC, 1975). O teor de lipídeos foi determinado segundo o procedimento descrito em Normas Analíticas do Instituto Adolfo Lutz (1985). O teor de umidade das sementes foi determinado, pesando-se cerca de $5 \mathrm{~g}$ de amostras e colocando em estufa a $105^{\circ} \mathrm{C}$ até a estabilização do peso. Após esse tempo, as amostras foram novamente pesadas e a matéria seca, determinada por diferença.

\section{RESULTADOS E DISCUSSÃO}

Os teores de umidade, lipídeos e proteína e a atividade de $\alpha$-galactosidase em sementes maduras de 10 espécies florestais são mostrados na Tabela 1 . A Soja da variedade Doko RC foi utilizada como referencial, uma vez que os parâmetros umidade, lipídeos e proteínas e atividade de a-galactosidase em suas sementes estão bem caracterizados (NIELSEN, 1996).

Dentre as espécies estudadas, as sementes de paina-rosa (Chorisia speciosa) apresentaram o maior teor de lipídeos e também alto teor de proteínas. Sibipiruna (Caesalpinia peltophoroides), ipê-amarelo (Tabebuia serratifolia) e ipê-roxo (Tabebuia velanedae) exibiram teores de lipídios maiores que de soja (Glycine max), entretanto os menores teores protéicos foram determinados nessas sementes. No entanto, a orelhade-negro (Enterolobium contortisiliquum) apresentou o maior teor de proteínas, inclusive superior ao de soja, considerada uma semente com elevado teor protéico. Elevada atividade de $\alpha$-galactosidase foi detectada no extrato de sementes de tamboril-da-mata (Platymiscium pubescens), o que levou essa espécie a ser selecionada como fonte produtora da $\alpha$ galactosidase, para caracterizações bioquímica e cinética.

Uma vez que a germinação das sementes pode induzir o aumento da atividade de enzimas hidrolíticas (KONTOS eSPYROPOULOS, 1996; GUIMARÃES, 2001), a atividade de $\alpha$-galactosidase foi determinada, durante a germinação, em extratos de sementes da espécie florestal tamboril da mata, bem como em sementes das leguminosas feijão-arroz (Vigna umbellata), ervilha (Pisum sativum) e soja (Glycine max) (Figura 1), utilizadas como controle, por se tratarem de espécies mais amplamente estudadas.

A atividade de $\alpha$-galactosidase aumentou consideravelmente em sementes de tamboril-da-mata e fedegoso no período de 24 a 72 h após a embebição, em relação às sementes usadas como controle. Resultados similares foram obtidos por Reis et al. (2003), que, trabalhando com sementes da espécie florestal Pterogine nitens, observaram aumento da atividade da $\alpha$-galactosidase durante a germinação. Atividades de $\alpha$-galactosidase sobre os substratos naturais encontrados nas sementes, rafinose e estaquiose e atividade de invertase sobre o substrato sacarose foram avaliadas nos extratos das sementes, após $72 \mathrm{~h}$ de embebição em água (Tabela 2).

Tabela 1 - Teores de umidade, lipídios e proteínas e atividade da $\alpha$-galactosidase em sementes maduras de soja e de espécies florestais

Table 1 - Contents of moisture, lipids, protein and $\alpha$-galactosidase activity from mature seeds of soybean and forest species

\begin{tabular}{lccc}
\hline Espécies Florestais & Umidade $(\%)$ & Lipídeos $(\%)$ & $\begin{array}{c}\text { Proteína }(\%) \\
\begin{array}{c}\text { Ativ. Específica } \\
\left(\mathrm{mM}^{\mathrm{min}} \mathrm{mg}^{-1}\right)\end{array}\end{array}$ \\
\hline Cassia grandis & $9,19 \pm 0,14$ & $1,64 \pm 0,05$ & $46,18 \pm 1,98$ \\
Schizolobium parahyba & $8,54 \pm 0,10$ & $4,08 \pm 0,27$ & $48,63 \pm 0,24$ \\
Tachigali multijuga & $6,69 \pm 0,07$ & $2,38 \pm 0,08$ & $36,37 \pm 0,22$ \\
Tabebuia serratifolia & $12,00 \pm 0,54$ & $22,96 \pm 0,38$ & $24,25 \pm 0,11$ \\
Tabebuia velanedae & $9,94 \pm 0,35$ & $21,38 \pm 0,36$ & $20,98 \pm 0,14$ \\
Enterolobium contortisiliquum & $4,82 \pm 0,06$ & $1,15 \pm 0,04$ & $50,30 \pm 0,31$ \\
Platymiscium pubescens & $13,53 \pm 0,57$ & $4,67 \pm 0,18$ & $43,90 \pm 0,76$ \\
Chorisia speciosa & $20,55 \pm 0,88$ & $31,12 \pm 0,15$ & $44,00 \pm 0,15$ \\
Caesalpinia peltophoroides & $9,69 \pm 0,57$ & $28,92 \pm 0,28$ & $25,22 \pm 0,41$ \\
Cedrela fissilis & $8,84 \pm 0,21$ & $16,07 \pm 0,24$ & $43,04 \pm 0,42$ \\
Glycine max & $11,05 \pm 0,45$ & $18,80 \pm 0,39$ & $41,45 \pm 0,24$ \\
\hline
\end{tabular}

R. Árvore, Viçosa-MG, v.29, n.4, p.535-543, 2005 
Sementes germinadas de tamboril-da-mata apresentaram as maiores atividades das enzimas hidrolíticas invertase e $\alpha$-galactosidase, inclusive superiores às de soja e ervilha, espécies tidas como grandes produtoras de $\alpha$-galactosidase. Segundo Dey e Pridham (1972) e Modi et al. (2000), várias leguminosas, como soja e ervilha, acumulam grande quantidade de oligossacarídeos de rafinose (RO) nos estádios finais de desenvolvimento do grão e são degradados por $\alpha$-galactosidases e invertases no início da germinação, fornecendo a energia inicial para o desenvolvimento do embrião. Uma vez que maior atividade de $\alpha$ galactosidase foi detectada em sementes de tamborilda-mata após $72 \mathrm{~h}$ de embebição, tal resultado indicou que essa espécie tem grande potencial para produção da $\alpha$-galactosidase. Assim, a enzima foi purificada e caracterizada a partir dessa fonte vegetal.

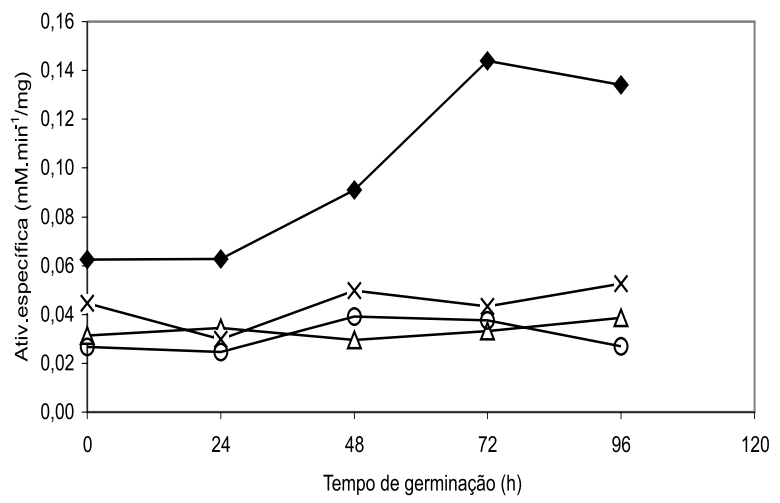

Figura 1 - Perfil da atividade de $\alpha$-galactosidase, usandose o substrato rNPaGal, em sementes de Platymiscium pubescens $(\bullet)$, Vigna umbellata $(\Delta)$, Glycine max (X) e Pisum sativum (O), durante a germinação.

Figure 1 -Profile of $\alpha$-galactosidase activity against $r N P a G a l$ from seeds of Platymiscium pubescens ( $\bullet$ ), Vigna umbellata $(\Delta)$, Glycine max $(X)$ and Pisum sativum $(O)$ during germination.
No processo de purificação da $\alpha$-galactosidase, a fração protéica contendo atividade enzimática precipitada com $50 \%$ de sulfato de amônio (A50) foi ressuspendida e submetida à cromatografia em coluna Sephacryl S-200, resultando na separação de duas frações (F1 e F2) com atividade de $\alpha$-galactosidase. A fração F1, por apresentar maior grau de purificação $(26,21$ vezes) e uma taxa de recuperação de $49 \%$, foi utilizada na seqüência do processo, sendo submetida à cromatografia em coluna de Concanavalina-A (Figura 2). Foram obtidas duas formas enzimáticas (C1 e C2) altamente purificadas, como indicado por suas atividades específicas (Tabela 3).

As $\alpha$-galactosidases $\mathrm{C} 1$ e $\mathrm{C} 2$ de $P$. pubescens foram purificadas 14,71 e 98,48 vezes, com rendimentos de 6 e $31 \%$, respectivamente. Similarmente, duas formas de $\alpha$-galactosidases foram purificadas de sementes de Cassia sericea germinadas (BHASKAR et al., 1990).

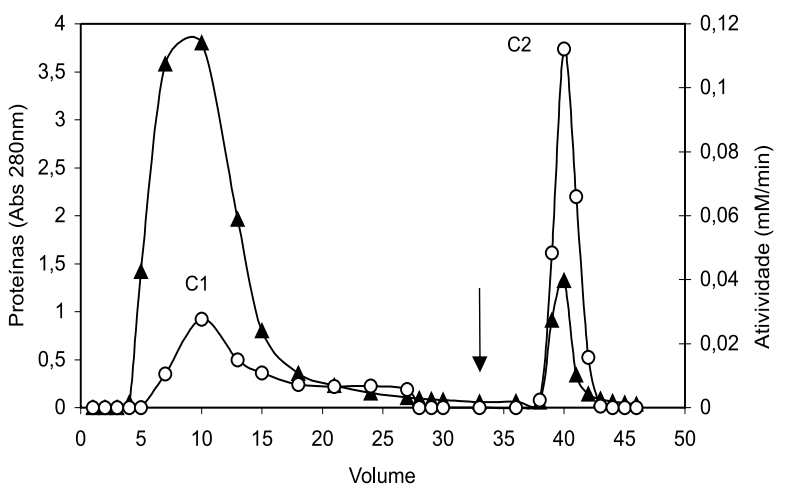

Figura 2 - Perfil de eluição da $\alpha$-galactosidase de sementes germinadas de Platymiscium pubescens em coluna de concanavalina-A Sepharose. Concentração de proteína $(\boldsymbol{\Delta})$, atividade enzimática $(\mathrm{O})$ e $(\downarrow)$ eluição com $0,1 \mathrm{M}$ de metil-a-D-manosídeo.

Figure 2-Elution profile of the $\alpha$-galactosidase from germinating Platymiscium pubescens seeds on a concanavalinA Sepharose column. Protein concentration ( $\mathbf{\Delta})$, enzyme activity $(O)$ and $(\downarrow)$ elution with $0.1 \mathrm{M}$ methyla-D-mannoside.

Tabela 2 - Atividade rafinolítica e de invertase em sementes de leguminosas após 72 h de embebição Table 2 - Raffinolytic and invertase activities from legume seeds 72 h after imbibition

\begin{tabular}{lccr}
\hline Espécie & & Atividade Enzimática $\left(\mathrm{mM} \cdot \mathrm{min}^{-1} \mathrm{mg}^{-1}\right)$ & \\
\cline { 2 - 5 } & Sacarose & Rafinose & Estaquiose \\
\hline Platymiscium pubescens & $0,143 \pm 0,011$ & $0,171 \pm 0,014$ & $0,121 \pm 0,011$ \\
Vigna umbellata & $0,072 \pm 0,006$ & $0,082 \pm 0,007$ & $0,113 \pm 0,010$ \\
Glycine max & $0,102 \pm 0,010$ & $0,155 \pm 0,013$ & $0,117 \pm 0,011$ \\
Pisum sativum & $0,074 \pm 0,006$ & $0,108 \pm 0,010$ & $0,076 \pm 0,005$ \\
\hline
\end{tabular}


Tabela 3 - Sumário das etapas de purificação das $\alpha$-galactosidases de sementes germinadas de Platymiscium pubescens Table 3 - Summary of the purification steps of the $\alpha$-galactosidases from germinating Platymiscium pubescens seeds

\begin{tabular}{|c|c|c|c|c|c|}
\hline Etapa de Purificação & $\begin{array}{l}\text { Proteína } \\
\text { Total mg }\end{array}$ & $\begin{array}{c}\text { Atividade Total } \\
\text { mM.min }{ }^{-1}\end{array}$ & $\begin{array}{c}\text { Atividade Específica } \\
\text { mM.min } \mathrm{min}^{-1} \mathrm{mg}^{-1}\end{array}$ & $\begin{array}{c}\text { Fator de } \\
\text { Purificação X }\end{array}$ & $\begin{array}{c}\text { Recuperação } \\
\% \\
\end{array}$ \\
\hline Extrato bruto & 2244,00 & 21,20 & 0,009 & 1 & 100 \\
\hline Sulfato de Amônio (30-50\%) & 758,00 & 17,30 & 0,023 & 2,43 & 82 \\
\hline Sephacryl S-200 & 42,29 & 10,42 & 0,246 & 26,21 & 49 \\
\hline \multicolumn{6}{|l|}{ Con A-Sepharose } \\
\hline $\mathrm{C} 1$ & 9,40 & 1,30 & 0,138 & 14,71 & 6 \\
\hline $\mathrm{C} 2$ & 7,00 & 6,48 & 0,926 & 98,48 & 31 \\
\hline
\end{tabular}

As $\alpha$-galactosidases $\mathrm{C} 1$ e $\mathrm{C} 2$ apresentaram $\mathrm{pH}$ 5,5 como ótimo para sua atividade (Figura $3 \mathrm{~A}$ ) e atividades máximas a 50 e $55^{\circ} \mathrm{C}$, respectivamente. Uma redução acentuada nessas atividades foi observada entre as temperaturas de $60-70{ }^{\circ} \mathrm{C}$, sendo a $70^{\circ} \mathrm{C}$ a atividade enzimática nula (Figura 3B). Os valores ótimos de $\mathrm{pH}$ e temperatura encontrados foram próximos daqueles determinados para $\alpha$-galactosidases de sementes de soja em germinação (CRUZe SILVA, 1986), de cotilédones de Vigna unguiculata (OLIVEIRA-NETO et al., 1998), de amendoim (BRYANT e RAO, 2001) e do fungo Aspergillus fumigatus (De REZENDE e FELIX, 1999).

Ambas as formas enzimáticas $\mathrm{C} 1$ e $\mathrm{C} 2$ foram moderadamente termoestáveis (Figura 4), mantendo aproximadamente $70 \%$ de suas atividades originais quando pré-incubadas a $45^{\circ} \mathrm{C}$ por $180 \mathrm{~min}$. Entretanto, a $50{ }^{\circ} \mathrm{C}$, com 30 min de pré-incubação, a C1 perdeu completamente a atividade, enquanto a $\mathrm{C} 2$ manteve apenas $40 \%$ da atividade original, após $180 \mathrm{~min}$ de incubação. A $50^{\circ} \mathrm{C}$, a meia-vida das $\alpha$-galactosidases $\mathrm{C} 1$ e C2 foram de 66 e de $232 \mathrm{~min}$, respectivamente. Puchart et al. (2000), trabalhando com $\alpha$-galactosidase de Thermomyces lanuginosus, encontraram meia-vida de $3 \mathrm{~h}$ a $65^{\circ} \mathrm{C}$, e Guimarães et al. (2001) constituíram, a $30^{\circ} \mathrm{C}$, meia-vida de 254 e de $1.199 \mathrm{~min}$, respectivamente, em duas $\alpha$-galactosidases de sementes de soja.

Os valores de $\mathrm{K}_{\mathrm{M} \text { ap }}$, tendo-se o $\rho \mathrm{NP} \alpha \mathrm{Gal}$ como substrato (Tabela 4), foram comparáveis àqueles determinados para $\alpha$-galactosidase de sementes de soja em germinação(CRUZe SILVA, 1986; GUIMARÃES et al., 2001) e para $\alpha$-galactosidase de Thermomyces lanuginosus (PUCHART et al., 2000). Os valores de $\mathrm{K}_{\mathrm{M} \mathrm{ap}}$ para a rafinose (Tabela 4 ) foram próximos daqueles determinados para $\alpha$-galactosidase purificada de sementes de soja madura (PORTER et al., 1990), mas menores do que aqueles descritos para a rafinose e as enzimas de Aspergillus fumigatus (De REZENDE e FELIX, 1999) e de amendoim (BRYANT e RAO, 2001).

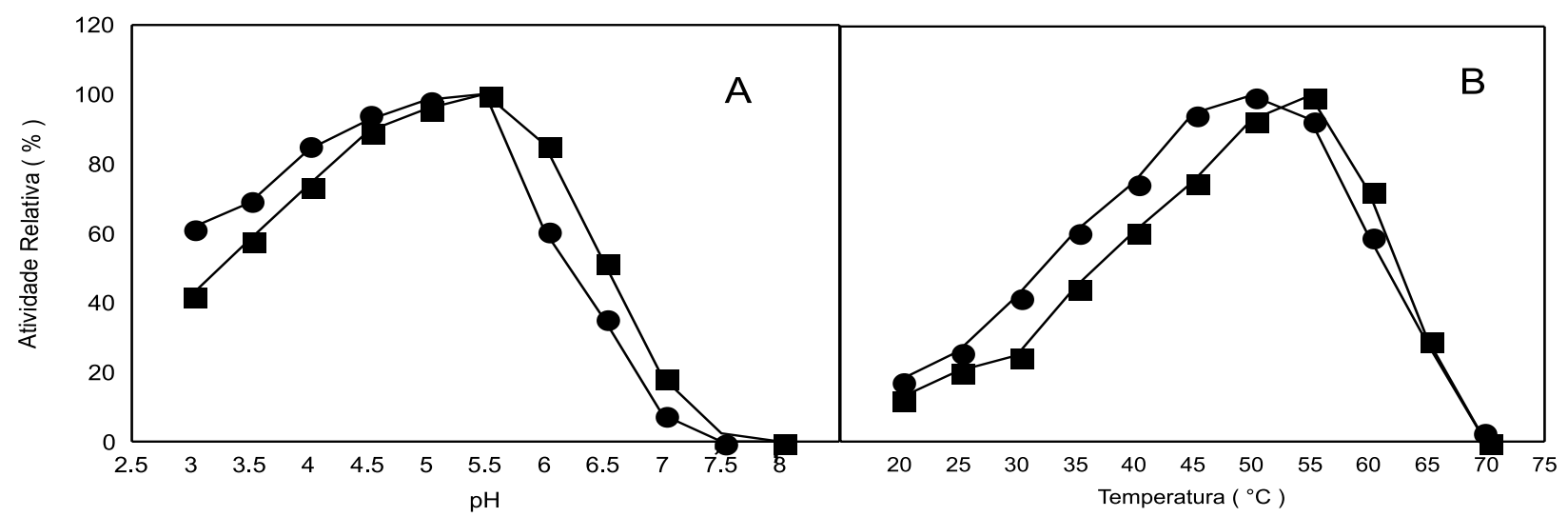

Figura 3 - Efeitos de pH (A) e temperatura (B) na atividade das $\alpha$-galactosidases $(\mathrm{C} 1, \bullet$; 2 , $\mathbf{\square})$ de sementes germinadas de Platymiscium pubescens.

Figure $3-p H(A)$ and temperature $(B)$ effects on the activity of $\alpha$-galactosidases $(C 1, \bullet ; C 2, \mathbf{\square})$ from germinating Platymiscium pubescens seeds.

R. Árvore, Viçosa-MG, v.29, n.4, p.535-543, 2005 


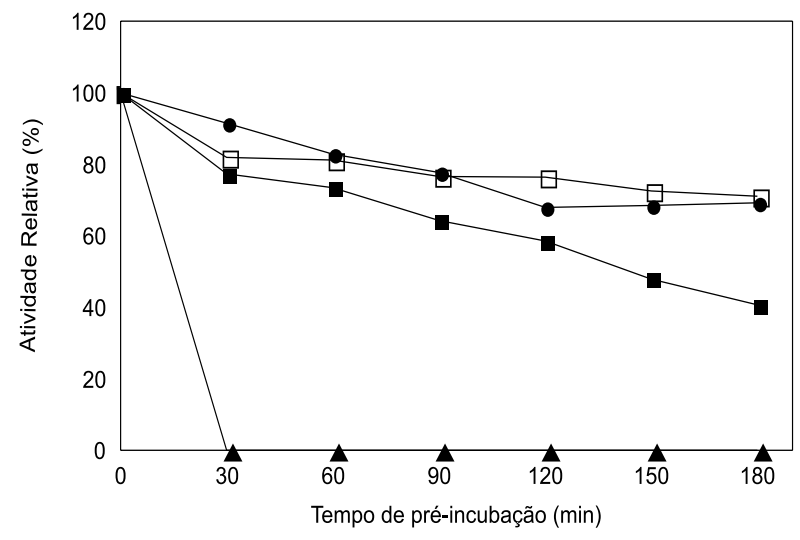

Figura 4-Efeito da temperatura na estabilidade das $\alpha$-galactosidases de sementes germinadas de Platymiscium pubescens. As preparações enzimáticas foram pré-incubadas a $45^{\circ} \mathrm{C}, \mathrm{C} 1(\bullet), \mathrm{C} 2(\square)$ ou $50^{\circ} \mathrm{C}, \mathrm{C} 1(\mathbf{\Delta}), \mathrm{C} 2($ por $3 \mathrm{~h}$ e ensaiada a $37^{\circ} \mathrm{C}$.

Figure 4 -Temperature effects on the stability of the $\alpha$ galactosidase from germinating Platymiscium pubescens seeds. Enzyme preparations were preincubated at $45^{\circ} \mathrm{C}, \mathrm{Cl}(\mathbf{\bigcirc}), \mathrm{C2}(\square)$ or $50^{\circ} \mathrm{C}$, $C 1(\mathbf{\Delta}), C 2(\mathbf{\square})$ for up to $3 h$ and the assays run at $37^{\circ} \mathrm{C}$.

Tabela 4 - Valores de $\mathrm{K}_{\mathrm{M} \text { ap }}$ e $\mathrm{V}_{\text {max ap }}$ da hidrólise de $\rho \mathrm{NP} \alpha \mathrm{Gal}$, rafinose e melibiose pelas $\alpha$-galactosidases de sementes germinadas de Platymiscium pubescens

Table 4- $K_{M a p p}$ e $V_{\max a p p}$ values for hydrolysis of $\rho N P \alpha G a l$, raffinose and melibiose by $\alpha$-galactosidases from germinating Platymiscium pubescens seeds

\begin{tabular}{ccccccc}
\hline & \multicolumn{2}{c}{$\rho \mathrm{NP \alpha Gal}$} & \multicolumn{2}{c}{ Rafinose } & \multicolumn{2}{c}{ Melibiose } \\
\cline { 2 - 7 } & $\begin{array}{c}\mathrm{K}_{\mathrm{M} \text { ap }} \\
(\mathrm{mM})\end{array}$ & $\begin{array}{c}\mathrm{V}_{\text {max ap }} \\
\left(\mathrm{mM} \cdot \mathrm{min}^{-1}\right)\end{array}$ & $\begin{array}{c}\mathrm{K}_{\mathrm{M} \text { ap }} \\
(\mathrm{mM})\end{array}$ & $\begin{array}{c}\mathrm{V}_{\text {max ap }} \\
\left(\mathrm{mM} \cdot \mathrm{min}^{-1}\right)\end{array}$ & $\begin{array}{c}\mathrm{K}_{\mathrm{M} \text { ap }} \\
(\mathrm{mM})\end{array}$ & $\begin{array}{c}\mathrm{V}_{\text {max ap }} \\
\left(\mathrm{mM}^{-1} \text { min }^{-1}\right)\end{array}$ \\
\hline $\mathrm{C} 1$ & 0,54 & 0,10 & 5,03 & 0,04 & - & - \\
$\mathrm{C} 2$ & 0,78 & 0,77 & 5,09 & 0,24 & 0,70 & 0,03 \\
\hline
\end{tabular}

As atividades de $\mathrm{C} 1$ e de $\mathrm{C} 2$ tiveram diminuição expressiva em presença de SDS e moderada em presença de melibiose e galactose, ressaltando-se que o cobre inibiu fortemente a atividade da $\mathrm{C} 2$ e totalmente a da C1 (Tabela 5). De forma semelhante, as atividades das $\alpha$-galactosidases de Vicia sativa e de Prunus amygdalus foram diminuídas em presença de cobre (DEY e PRIDHAM, 1972). EDTA e iodoacetamida não influenciaram a atividade de $\mathrm{C} 1$ e $\mathrm{C} 2$, indicando que não há dependência de íons metálicos e de grupo SH (sulfidrila) livre, essenciais à catálise.
Tanto a C1 quanto a C2 não hidrolisaram substratos sintéticos contendo resíduos de açúcar diferentes de galactose ou contendo galactose na posição $\beta$ (Tabela 6).

Altas atividades sobre rafinose e estaquiose sugerem que as duas formas de $\alpha$-galactosidase de tamborilda-mata podem atuar nas sementes em germinação, hidrolisando os RO. No entanto, a hidrólise da lactose, maltose e sacarose acreditam que essas enzimas não apresentam especificidade absoluta ou que, na preparação, existiam outras proteínas com atividade enzimática.

Tabela 5 - Efeito de íons, açúcares e outros efetores na atividade das $\alpha$-galactosidases de sementes germinadas de Platymiscium pubensens

Table 5 - Effect of ions, sugars and other effectors on $\alpha$ galactosidases from germinating Platymiscium pubensens seeds

\begin{tabular}{|c|c|c|}
\hline \multirow[t]{2}{*}{ Composto* } & \multicolumn{2}{|c|}{ Atividade Relativa (\%) } \\
\hline & $\mathrm{C} 1$ & $\mathrm{C} 2$ \\
\hline Controle & 100 & 100 \\
\hline D-Galactose & 48 & 54 \\
\hline D-Glicose & 100 & 96 \\
\hline Sacarose & 92 & 96 \\
\hline Rafinose & 90 & 100 \\
\hline Melibiose & 72 & 62 \\
\hline $\mathrm{CuSO}_{4}$ & 0 & 40 \\
\hline $\mathrm{MgCl}_{2}^{4}$ & 94 & 100 \\
\hline $\mathrm{KCl}^{2}$ & 100 & 95 \\
\hline $\mathrm{NaCl}$ & 100 & 94 \\
\hline $\mathrm{CaCl}_{2}$ & 96 & 100 \\
\hline SDS $^{2}$ & 6 & 0 \\
\hline Beta-Mercaptoetanol & 100 & 100 \\
\hline EDTA & 96 & 100 \\
\hline Iodoacetamida & 100 & 92 \\
\hline
\end{tabular}

* A concentração final dos compostos foi de $2 \mathrm{mM}$.

Tabela 6 - Hidrólise de vários substratos pelas $\alpha$-galactosidases de sementes germinadas de Platymiscium pubensens Table 6 -Hydrolysis of several substrates by the $\alpha$-galactosidases from germinating Platymiscium pubescens seeds

\begin{tabular}{lccc}
\hline Substratos & Concentração $(\mathrm{mM})$ & \multicolumn{2}{c}{ Atividade Relativa (\%) } \\
\cline { 2 - 4 } & & $\mathrm{C} 1$ & $\mathrm{C} 2$ \\
\hline$\rho$ NP- $\alpha \mathrm{Gal}$ & 0,5 & 100 & 100 \\
Rafinose & 10,0 & 94 & 100 \\
Estaquiose & 10,0 & 63 & 56 \\
Melibiose & 10,0 & 59 & 20 \\
Sacarose & 10,0 & 53 & 71 \\
Maltose & 10,0 & 53 & 21 \\
Lactose & 10,0 & 76 & 6 \\
$\rho N P-\alpha G l c$ & 0,5 & 0 & 0 \\
$\rho N P-\alpha$ Ara & 0,5 & 0 & 0 \\
$\rho N P-\alpha X i l$ & 0,5 & 0 & 0 \\
$\rho N P-\alpha M a n$ & 0,5 & 0 & 0 \\
$\rho N P-\beta G a l$ & 0,5 & 0 & 0 \\
$o$ NP- $\beta$ Gal & 0,5 & 0 & 0 \\
\hline
\end{tabular}

R. Árvore, Viçosa-MG, v.29, n.4, p.535-543, 2005 


\section{CONCLUSÕES}

- Sementes das espécies florestais Chorisia speciosa, Caesalpinia peltophoroides, Tabebuia serratifolia e Tabebuia velanedae são muito ricas em lipídeos, enquanto sementes de Enterolobium contortisiliquum, Schizolobium parahyba e Cassia grandis o são em proteínas.

- Atividade específica de $\alpha$-galactosidase de sementes de Platymiscium pubescens aumenta durante a germinação, tendo sido identificadas duas formas da enzima ( $\mathrm{C} 1$ e C2), com atividade máxima em $\mathrm{pH}$ de 5,5 e em 50 e $55^{\circ} \mathrm{C}$, respectivamente.

- As $\alpha$-galactosidases de sementes germinadas de $P$. pubescens apresentam estabilidade térmica moderada, e a forma $\mathrm{C} 2$ exibe maior estabilidade em comparação com a forma $\mathrm{C} 1$.

- As $\alpha$-galactosidases C1 e C2 de P.pubescens hidrolisam os substratos naturais melibiose, rafinose e estaquiose, indicando potencial para aplicações biotecnológicas.

\section{AGRADECIMENTOS}

Os autores agradecem à FAPEMIG o suporte financeiro para a realização deste trabalho.

\section{REFERÊNCIAS BIBLIOGRÁFICAS}

ASSOCIATION OF OFFICIALANALYTICAL CHEMISTS - AOAC. Official methods of analysis of the Association of Official Analytical Chemists. Washington: 1975. $1094 \mathrm{p}$.

BERGMEYER, H.U.; BERNT, E. Determination of glucose with oxidase and peroxidase. In: BERGMEYER, H.U. (Eds), Methods of enzymatic analysis. Weinheim: Verlag Chemic, 1974. p.1205-1215.

BHASKAR, B.; RAMACHANDRA, G.; VIRUPAKSHA, T.K. Alpha galactosidase of germinating seeds of Cassia sericea $\mathrm{Sw}$.

Journal of Food Biochemistry, v.14, p.45$59,1990$.

BOM, I.; WASSENAAR, V.D.; BOOT, J. Hybrid affinity chromatography of $\alpha$-galactosidase from Verbascum thapsus L. Journal of

Chromatography A, v. 808, p. 133-139, 1998.
BORGES, E.E.L. et al. Comportamento fisiológico de sementes osmocondicionadas de Platymiscium pubescens Micheli (Tamboril da Mata). Revista Árvore, v. 26, p. 603-613, 2002.

BRADFORD, M.M. A rapid and sensitive method for the quantitation of microgram quantities of protein utilizing the principle of protein-dye binding. Analytical Biochemistry, v.72, p.248-254, 1976.

BRYANT, R.J.; RAO, D.R. Purification and characterization of alpha-galactosidase from peanuts. Journal of Food Biochemistry, v. 25 , p. 139-156, 2001.

CARNEIRO, M.A.C. et al. Micorriza arbuscular em espécies arbóreas e arbustivas nativas de ocorrência no Sudeste do Brasil. Cerne, v. 4, p.129-145, 1998.

CARVALHO, P.E.R. Espécies florestais brasileiras: recomendações silviculturais, potencialidades e uso da madeira. Colombo: EMBRAPA-CNPF / Brasília: EMBRAPA SPI, 1994.

CORCHETE, M.P.; GUERRA, H. $\alpha$ and $\beta$ galactosidase activities during germination of lentil seeds. Plant Physiology and Biochemistry, v. 25, p. 105-109, 1987.

CRUZ, R.; SILVA, A.L. Soybean (Glycine max), endogenous alpha-galactosidase and invertase during the germinative process. Arquivos de Biologia e Tecnologia, v. 29, p. 435-443, 1986.

DEY, P.M.; PRIDHAM, J.B. Biochemistry of $\alpha$ galactosidases. Advanced Enzymology, v.36, p.91-130, 1972.

DEY, P.M. Biochemistry of alfa-galactosidic linkages in the Plant kingdom. Advanced Carbohydrates Biochemistry, v. 37, p.273283, 1980.

DE REZENDE, S.T.; FELIX, C.R. Production and characterization of raffinose-hydrolysing and invertase activities of Aspergillus fumigatus. Folia Microbiologica, v. 44, p. 191-195, 1999. 
FALCO, A.L.P.; DURRANT, L.R.; FRANCO, T.T. Purification of $\alpha$-galaactisidase from seeds of Sesbania marginata. Brazilian Journal of Chemical Engineering, v 17, p. 819-825, 2000.

FUJIMOTO, Z. et al. Crystal structure of rice $\alpha$ galactosidase complexed with D-galactose. The Journal of Biological Chemistry, v. 278, p. 20313-20318, 2003.

GAO, Z.; SCHAFFER, A. A. A novel alkaline $\alpha$ galactosidase from melon fruit with a substrate preference for raffinose. Plant Physiology, v.119, p. 979-987, 1999.

GUIMARÃES, V.M. et al. Characterization of $\alpha$ galactosidase from germinating soybean seed and their use for hydrolysis of oligosaccharides. Phytochemistry, v. 58, p. 67-73, 2001.

HYAMS, D. Curve Expert 1.3: A comprehensive curve fitting system for Windows. Copyring (c). 1997.

INSTITUTO ADOLFO LUTZ - IAL. Normas analíticas do Instituto Adolfo Lutz; métodos físicos e químicos para análise de alimentos. 3 . ed. São Paulo: 1985. v. 1. p. 533.

KANDLER, O.; HOPF, H. Metabolism and function of oligosaccharides. In: Biochemistry of plants. Carbohidrates. New York: Academic Press, 1980. v.15, p.117-131.

KIM, W.D. et al. $\alpha$-Galactosidase from cultured rice (Oryza sativa L. var. Nipponbare) cells. Phytochemistry, v. 61, p. 621-630, 2002.

KLITGAARD, B.B. Systematics of Platymiscium (Leguminosae: Papilionoideae: Dalbergiae): taxonomy, morphology, ontogeny and phylogeny. 1995. $168 \mathrm{f}$. Thesis (PhD.) University of Aarhus, Aarhus, 1995.

KONTOS, F.; SPYROPOULOS, C.G. Seed coat inhibits the production of a-galactosidase and endo- $\beta$-mannanase in the endosperm of developing carob seeds. Plant Physiology and Biochemistry, v. 34, p. 787-793, 1996.

\author{
MARANGON, L.C. Florística e \\ fitossociologia de área de floresta \\ estacional semidecidual visando \\ dinâmica de espécies florestais \\ arbóreas no município de Viçosa - MG. \\ 1999. 145 f. Tese (Doutorado em Ecologia e \\ Recursos Naturais) - Universidade de São Carlos, \\ São Carlos, 1999.
}

MILLER, G.L. Use of dinitrosalicylic acid reagent for determination of reducing sugar. Analytical Chemistry, v. 31, p. 426-428, 1956.

MODI, A.T., MCDONALD, M.B.; STREETER, J.G. Soluble carbohydrates in soybean seeds during developoment and imbibition. Seed Science and Technology, v. 28, p. 115-127, 2000.

OLIVEIRA-NETO, O.B. et al. Partial purification and properties of cotiledonary $\alpha$-galactosidase from three cultivars of Vigna unguiculata. Revista Brasileira de Fisiologia Vegetal, v. 10, p. 91-96, 1998.

PETERSON, G.L. Review of the Folin phenol protein quantitation method of Lowry, Rosebrough. Farr and Randall. Analytical Biochemistry, v.100, p. 201-220, 1979.

PUCHART, V. et al. Purification and characterization of $\alpha$-galactosidase from a thermophilic fungus Thermomyces lanuginosus. Biochimica et Biophysica Acta, v. 1524, p. 27-37, 2000.

PORTER, J.E.; HERRMANN, K.M.; LADISH, M.R. Integral Kinetics of $\alpha$-galactosidase purified from Glycine max for simultaneous hydrolysis of stachyose and raffinose. Biotchnology and Bioengineering, v. 35, p. 15-22, 1990.

REID, J.S.G. Structure and function in legume-seed polysaccharides, In: BRETT, C.T.; HILLMAN, J.R. (Eds.) Biochemistry of plant cell walls. Cambridge: Cambridge University Press, 1985. p.259-268.

SMART, E.L.; PHARR, D.M. Characterization of $\alpha$ galactosidase from cucumber leaves. Plant Physiology, v. 66, p. 731-734, 1980.

R. Árvore, Viçosa-MG, v.29, n.4, p.535-543, 2005 